\title{
Some like it hot? Elite female athlete perspectives on competing in extreme climatic conditions at world championship sports events
}

\section{Purpose}

This paper explores perspectives of elite female athletes competing at world championship sports events, hosted in extreme climatic conditions. From the athlete perspective, it examines the implications of decisions by global sports federations when selecting host cities and the subsequent impacts upon elite athletes competing in unfavourable climates.

\section{Design / methodology / approach}

Using an exploratory case study approach at the 2019 IAAF World Athletics Championships in Doha, Qatar, this paper explores insider perspectives of four elite female participants competing in the Marathon. Adopting the 'elite interviewing' technique, and based on event participant experiences, the paper prioritises the perspective and 'voice' of the athlete.

\section{Findings}

Four key themes emerged from the data. These were (i) the importance of training and preparation; (ii) unique challenges of competition day; (iii) elite athlete retrospection; and (iv) prioritising the perspectives of elite athletes at international sports events. The findings highlight the challenges of managing athlete preparation and performance at world championship events hosted in extreme climatic conditions.

\section{Originality / value}


This paper secures unique insider access to elite level female endurance athletes competing at world championship events. The study makes a contribution to knowledge in event studies by introducing concepts of 'elite event interviewing' and the 'athlete-event paradox'.

\section{Research limitations / implications}

The sample size for this study whilst relatively small, is unique. This reflects challenges accessing elite athletes, their reluctance to be interviewed, and the small pool of elite athlete talent available. Given these practical barriers, this represents a good sample size.

Keywords: International sports events; elite interviewing; endurance sport; extreme climate; marathon 


\section{Some like it hot? Elite female athlete perspectives on competing in extreme climatic conditions at world championship sports events}

\section{Introduction}

The importance of the athlete is an undervalued and often unrecognised component of successful international sports events championships (Shipway and Fyall, 2012). According to Parent and Chappelet (2017), global sports events exist solely because of the athletes. Previous studies have focused on the perspectives and opinions of spectators and fans at global sports events (Wann and Pierce 2005, Sarstedt et al., 2014). Given that athletes play a leading role in the successful delivery of international sports events, sports policy is rarely carried out in consultation with athletes, and almost never in partnership with athletes (Houlihan 2004; Pitts and Zhang 2016). This study explores the athlete voice in forming and influencing the future policy and direction for hosting International Sports Events (ISEs).

The impact of globalisation is evident in the field of international sports events (Parent and Chappelet, 2017). Using case studies from Africa and Gulf state countries, Shipway and Miles (2019) investigated the trend for the relocation and movement of high-profile ISEs by international sports federation for a variety of non-sport related purposes. This trend towards new host nations often includes non-competition focused decisions by sporting bodies and sporting officials in the selection process of host venues for important competitions (Maennig and Zimbalist, 2012). Similarly Dowse and Fletcher (2018) highlight the interplay of the global shift in the hosting of international sports events outside of the more traditional 'western world' host countries. 
The prevailing climatic conditions of many new emerging host nations and ongoing climatic change presents major challenges for international sports events; however, the impact of weather on sport events is not well studied (Matzarakis and Fröhlich, 2015). These issues highlight the urgency of sourcing alternative solutions for athletes both before and during competition, especially when occurring under extreme climatic conditions (Maughan and Shirreffs, 2004). Unfortunately, it is the active event participants, the elite athletes, who are the most directly affected by the requirement to 'perform' in endurance events like the marathon in unfavourable climates.

The aim of this paper is to explore the perspectives, impacts and requirements of elite athletes competing in unfavourable climatic conditions at world championship sports events. In doing so, this study (i) examines the central role of the elite athlete as an integral part of highprofile international sport events, (ii) investigates climatic challenges that elite athletes face due to the relocation of international sports events and championships to non-western countries, and (iii) explores the views and perspectives of elite athletes as a key stakeholder and conduit for future knowledge transfer and management of information for ISEs. Throughout the study priority is given to the athlete voice. Through an athlete-focused approach, the contribution of this study is to critically examine ISEs from the athlete perspective and advocate calls for organising committees of high-profile international sports events to prioritise athlete welfare. More fundamentally, from an ethical perspective, this study raises awareness of the challenging role for elite athletes at international sports events (ISEs). 


\section{An overview of existing literature}

Athletes and fans are the main 'actors' at international sports events (Shipway and Fyall, 2012). The following literature review will explore the connection between the centrality of the athlete and the ongoing development and globalisation of international sports events (Dowse and Fletcher, 2018). It will address issues linked to the selection of host nations for major tournaments and world championships, and subsequent challenges facing elite athletes competing in extreme and unfavourable climatic conditions.

\subsection{Globalisation and climatic implications of moving ISEs to 'new' nations}

The development of globalisation in sport has been described by Jarvie (2006, p.93) as an 'increase in the number of international sporting agencies; the growth of global forms of communication; the development of international sport competitions and prizes; the increasingly international acceptance of rules governing primarily western sport forms.'

The impact of globalisation is apparent with the number of countries participating in international sports events and the associated reduction of borders between countries and nationalities. The intensifying globalisation of sport (Shipway and Fyall, 2012) has made it easier for athletes to represent their countries and origins at international sports events (Ishac, 2018) and led to an increase in their social value (Miller et al., 2001).

The monopolisation of the west over the host city selection process is reflected in the focus of 
host cities in the west (Close et al., 2006). In this process, the globalisation of sport has further strengthened the domination of the west over non-western countries (Dashper et al., 2015). However, the shift of global economic power towards the east, partly due to the increasing economic power of China and the resource-rich Gulf state region, combined with the high financial costs, has seen the locations for major sports events changing (Pop et al., 2016).

A central aspect when staging international sports events that has not received sufficient coverage and importance is the climatic conditions of the host country. However, it is precisely these conditions that pose the greatest threat to the health and performance of athletes, when competitors are exposed to hot and humid environments (Montain et al., 2007). As Reiche and Sorek (2019) identify, climate as an important factor in the sports environment has not been sufficiently investigated. High-profile mega sport events such as the Tokyo Olympic and Paralympic Games and the Qatar FIFA World Cup, which take place in summertime, present major logistical challenges in planning and implementation. The Tokyo Games will take place under the most difficult meteorological conditions (Szubski, 2019). Kakamu et al., (2017) highlighted that Tokyo Games take place under extremely high temperature conditions and present a high risk of heat illness amongst the elite athletes who are competing. Likewise, Henderson (2016) questioned the suitability of certain host nations when there is potential risk to human health.

\subsection{The athlete-event paradox}

Increasingly, International Sports Events (ISEs) are viewed as attractive opportunities for developing nations seeking to enhance their global profile in terms of both global prestige, 
economic development and tourism (Chappelet and Parent, 2017). The dimension of changing host locations, often due to the increasingly competitive bidding agenda of many host nations and a desire to manage destination image and political agendas, represents a proposition that has major implications for the athletes competing. Hence, an athlete-event paradox often exists. On the one hand, developing countries may secure a successful bid for hosting a major international sporting tournament precisely because global sports federations and wider political entities believe that hosting that tournament will be a stabilising force and ethical 'force for good' in building the reputation of sport in developing countries (Dowse and Fletcher, 2018). It represents part of the 'soft power' influence and strategies of the international community (Grix and Lee, 2013). Equally, it is often the case that one of the main reasons why host nations in the developing world are chosen is because of the desire of international sporting communities and global governing sports federations to be seen to contributing actively to building better reputations for host countries and encouraging stability (Shipway and Miles, 2019). In contrast, developing countries will wish to secure ISEs to fulfil larger political aims, including enhancing national branding and international reputation (Knott et al., 2017). However, a significant athlete-event paradox exists here, whereby those bidding processes rarely consider the athletes who will be competing in often extreme and unfavourable climatic conditions.

A contrast exists between the strategic objectives of both global sports federations awarding tournaments to developing nations for their own 'soft power' reasons, and the host nations bidding more for political and/or image building reasons, with minimal if any consideration given to the impact and challenges for the elite athletes. In reality, this athlete-event paradox might not necessarily contribute towards enhancing elite athlete performance, and more fundamentally present a significant health risk for the elite athletes competing. 


\subsection{Challenges facing elite athletes competing in extreme climatic conditions}

Heat is by far the most challenging of all the elements that endurance athletes face in daily training and competition (Maughan and Shirreffs, 2004), and there are numerous studies on the effects of heat on endurance athletes. Guy et al., (2015) analysed performance differences between elite athletes who participated in the World Athletics Championships between 1999 and 2011 , in both hot environments $\left(>25^{\circ} \mathrm{C}\right)$ and cooler, temperate conditions $\left(<25^{\circ} \mathrm{C}\right)$. Their results demonstrated that athletes experienced a 3\% drop in performance in the endurance races affected by the heat.

El Helou et al., (2012) reached a similar conclusion in their analysis of finishers of the three major marathons in Europe (Berlin, Paris and London) and three major American marathons (Boston, Chicago and New York). They found that the higher the temperature increase, the greater the decrease in performance of the runners. In addition, the study found that high heat and humidity levels not only potentially compromised performance, it also placed the athletes' health at risk. The recognition that athletes are affected by air temperature in combination with relative humidity was supported by Vihma (2010) who examined the percentage of non-finishers at the Stockholm Marathon in Sweden.

The human body has a narrow temperature range of $35^{\circ} \mathrm{C}$ to $41^{\circ} \mathrm{C}$ with an average value of $36.5^{\circ} \mathrm{C}$ to $37.5^{\circ} \mathrm{C}$, and this equilibrium is ensured by temperature control functions of the body, whereby the balance between heat production and heat loss is maintained (Casa, 1999). The illness patterns of athletes at major sports events caused by heat and movement were the second and third most common illnesses at the World Athletics Championships in Berlin (2009) and Daegu (2011) (Alonso, 2016). Based on experience gained from previous major 
sports events with regard to the health risks posed to athletes by environmental factors, the International Amateur Athletics Federation (IAAF) introduced measures to protect athletes whereby the potential effect of heat on athletes could be measured and a risk assessment provided (Chan, 2019). However, despite preventative measures, the elite athletes, a key stakeholder in the sports event process, are often subjected to competing in unfavourable conditions due to decisions taken by international governing bodies and federations when selecting host destinations and venues.

\subsection{Summary}

The existing literature on this topic has focused mainly on both spectator opinions (Ko et al., 2011, Ramchandani et al., 2017) and a number of medical studies on the physical effects of endurance sports in difficult climatic conditions (Suping et al., 1992, Garrett and Kirkendall, 2000, Cheuvront and Haymes 2001). This study will help provide a deeper understanding of individual elite athlete perceptions on the impact of climate on endurance runners.

Parent \& Chappelet (2017, p.125) highlight that 'without the athlete, there is no sport event and spectacle for consumers, there is no entertainment'. If we accept that sports fans and athletes are two central components of international sports events, then the decisions to host tournaments and world championships in countries with extreme climatic conditions presents significant new challenges for the athletes, especially with regard to the thermal combination of heat and humidity. It is the central proposal of this paper that there is a pressing need for international sport event organisers to place far greater emphasis on the athlete in both the preparation and delivery stages of the event (Greenwell et al., 2014). 


\section{Research methods}

This study utilised in-depth interviews to explore participants' stories, and to make sense and make clear connections between event experiences and aspirations (Shipway and Jones, 2008). Using the 'elite interviewing' technique, it was possible to gain a rich and unique view of the challenges and obstacles that elite athletes, at the very pinnacle of their sport, face when competing in extreme climatic conditions.

\subsection{An exploratory case study approach: The 2019 IAAF World Athletics}

\section{Championships in Doha}

Using an exploratory case study approach of the 2019 IAAF World Athletics Championships in Doha, Qatar, this paper explores the insider perspectives of four elite female participants competing in the highest profile and well-established endurance event of the Athletics calendar, the Marathon. The 2019 Championships was the seventeenth edition of the biennial, global athletics competition organised by the International Association of Athletics Federations, since renamed World Athletics.

The World Athletics Championships were held in September 2019, and are one example of the effects of hosting major global championships in a nation that combines high temperatures with high humidity. The suitability of the Qatari climate for elite sports competitions has long been controversial (Ingle, 2019) with temperatures rising to $46{ }^{\circ} \mathrm{C}$ and relative humidity of up to $100 \%$ during the summer season (Sofotasiou et al., 2015). To reduce the climatic impact for the 2019 World Athletics Championships and in preparation for the 2022 FIFA World Cup tournament, Qatar implemented technological measures to 
regulate heat in the stadiums, training grounds and fan zones using low-climate technology (Holt and Ruta, 2015). However, the major cause for concern is not the events held in stadiums that are cooled down to $23^{\circ} \mathrm{C}$, but at the marathon and walking competitions held outside of the main venues, on the streets of Doha. Consequently, of the 68 starters in the women's marathon on the opening day of the world championships in Doha, only 40 finished the marathon, with 28 female elite athletes not completing the event due to the climatic conditions (Ingle, 2019).

In the case of the 2019 Doha World Championships, the IAAF designed a 'flag system' to monitor conditions and either postpone or delay events until safer conditions prevailed. This ultimately resulted in the IAAF changing start times for all endurance events in Doha until around midnight due to the risks of starting earlier. A start under 'black flag' was seen as problematic because it did not comply with the medical guidelines of the IAAF, and would expose the athletes to heat-related illnesses and loss of performance. The IAAF and the Qatari local organising committee claimed they had taken all the necessary measures to minimise the heat-related hazards (Ingle, 2019). These measures included postponing the endurance competitions to midnight, distribution of necessary information to all members of the Athletics federations in the previous six months on preparing to compete in extreme heat, and the provision of increased refreshment points along the marathon route, to name a few.

\subsection{An overview of the sample}

The sample for this study comprised four $(n=4)$ elite female athletes ranging in age from 31 to 38 years, who participated in the marathon at the 2019 IAAF World Championships in Doha, Qatar. Two of the participants finished the race and two 'did not finish' (DNF). 
Noteworthy for this study was the geographical origin of the athletes as it is balanced between two climatically warm countries (athlete 1 and 2) and two climatically cold countries (athlete 3 and 4). Further information on the nationalities of the athletes has been withheld to protect their anonymity, as given the small number of competitors, highlighting their nationality would most certainly compromise their identity. All four athletes meet the term 'elite' as defined by Sheppard-Marks et al., (2020). Their qualification times ranged from the fastest time of approximately 02:32:00 (elite athlete 4, 38 years old from North America; 02:34:00 in Australasia; (elite athlete 2, 34 years old, from Mediterranean Europe), 02:35:00 in Europe (elite athlete 3, 34 years old, from Scandinavia) and 02:35:00 in Europe (elite athlete 1, 31 years old, from Mediterranean Europe).

All four elite female athletes were selected to participate in the 2019 IAAF world championships by their national Athletics federations based on their past and present athletic performances, their competition experiences, and meeting the criteria of the IAAF / World Athletics, the international governing body for the sport of Athletics. World Athletics portfolio of events covers track and field, cross country running, road running, race walking, mountain running, ultra-running, and for the purposes of this study, the marathon, a track and field based sports event, held over the distance of 26.2 miles / 42.1 kilometres (Shipway and Jones, 2008). Finally, given the international background of the participants, it was estimated that approximately $50 \%$ of the elite female athletes competing in the marathon event were non-native English speakers (Polio and Friedman, 2016). This was a partial limitation for the global diversity of the sample.

\subsection{Elite interviewing and events}


This paper makes a methodological contribution to knowledge in an event and festival context through the use of the elite interviewing technique (Sheppard-Marks et al., 2020), which are absent from critical event studies. Utilising the concept of elite interviewing, the findings explore the stories of four elite female athletes competing at the pinnacle of their athletic careers.

The term 'elite' is traditionally used to refer to those whose abilities and qualities mark them out as superior within a group, and elite athletes are no different (Sheppard-Marks et al., 2020). According to Sheppard-Marks et al., the differences in definitions of what constitutes an elite athlete has been used to describe those who have attended high level sports events like world championships or the Olympics, been members of national teams, played highlevel sport for a certain time period, or been professional athletes. An important area of qualitative research, elite interviewing as a method aims to fill the gap in our understanding of a group of people considered by many to be superior as a result of their power, talent or privileges (Sheppard-Marks et al., 2020). A small, but emerging area of social science research, elite interviewing explores the intricacies associated with interviewing elite participants (Lancaster 2017). By studying elite's, researchers are provided with a unique opportunity to understand the worldview of influential people who often have access to exclusive information that is not readily available to the public (Mikecz 2012).

In the context of event studies, very little is known about the social world in which elites exist, train and compete. As such, by studying them in a sports event context, researchers are provided with a unique opportunity to understand their worldview. One notable exception in a sports event context was the study by Dashper (2012) at the 2008 Beijing Olympic Games. Through interviews with elite (Olympic) athletes about their own event experiences, she 
was able to highlight implications for both human and animal welfare when competing in hot and humid conditions.

Access to elites can be particularly challenging due to the many barriers between the researcher and elite event participant. This is one of the reasons for the lack of research into elites, who can protect themselves from intrusion. These barriers can act as shields, protecting elites from scrutiny within their broader event or festival communities. For the purpose of this study the principles of elite interviewing can be applied to this sample of elite athletes who comprise a relatively small, but powerful group of 'in the know' female athletes (Mikecz 2012); Sheppard-Marks et al., 2020). The focus of the interviews was on the unique insight they possessed (of both training at competing at international sports events and being an elite athlete). In discussion on benefits of studying elite athletes, Shepherd-Marks et al., advocate the use of small samples of exceptional athletes to gain insight into the athletic world they inhabit. As such, the elite interviews undertaken for this study provided a unique dataset for analysis, offering a rare opportunity to understand their athlete event experiences.

Working with a sample of elites can generate issues and challenges around (i) access, (both physically and psychologically); (ii) the issue of asymmetry of power in interviews; (iii) rapport, trust and credibility; and (iv) the maintenance of emotional distance (Lancaster, 2017). The success of any research into elites is dependent on the ability of the researcher to gain access, and this success contributes directly to the nature and quality of the data obtained (Mikecz, 2012). Likewise, with regards to the asymmetry of power, the issue of power imbalance is a key discussion around elite interviewing (Boucher 2017), and can potentially present researchers with a number of practical challenges. The four athletes in this study could be considered 'powerful' in terms of knowledge, ability, privilege and their degree of 
public recognition. As such, we were aware of the need to avoid feelings of being what Delaney (2007) describes as 'status subordinates'. It was essential that any power differentials were navigated and minimised to ensure that a successful working relationship between the elite and ourselves, upon which the quality of qualitative research could be developed (Sheppard-Marks et al, 2020).

With regards to the prevailing asymmetry of the interview situation, the athletes were not in a position of power or dominance. Both of the researchers were highly knowledgeable about the social world of endurance athletes, technical language, and social situations of the elites which positioned them in a position of equality whereby the athletes were aware of the researcher's culture and background (Shipway, Holloway and Jones, 2013). Within the process of building rapport, trust and credibility with our elite sample, it was also important to further demonstrate in-depth knowledge of endurance distance running in order to enable trust to be established between ourselves and the elite athletes (Mikecz 2012). Thus, prior to the interviews, we were able to display our own credibility as both high performance athletes and widely published scholars in the field, and avoid any potential for the four elite athletes to promote a particular agenda. This also enabled us to establish challenging statements and provocations that led to new insights into this particular social world. Finally, maintaining emotional distance was a conscious process, given their elite athletic status. We were mindful to not automatically assume they 'knew better', or more than us, to be seduced by their elite position of influence, or to be 'star struck', and defer to their judgement (Delaney, 2007).

On average, the in-depth interviews lasted for approximately 60 minutes. Due to COVID restrictions and the diverse global locations of the elite athletes, the interviews were conducted by video conferencing platform (Shipway et al., 2021). The use of a live visual 
and auditory experience and sense of actual face-to-face interviewing can be implied, and recording of non-verbal, sensory and emotional signals is ensured (Krouwel et al., 2019). Furthermore, online video interviews offer the advantage that interviewees often feel more comfortable in the interview situation as they can choose the interview location themselves (Jones, 2014). A disadvantage of using online video interviews is that researchers and respondents must have access to necessary technologies and feel confident to use them.

Participant consent forms and information sheets were circulated ahead of the interviews, and signed consent forms were returned electronically. Prior to the interviews, athletes were also provided with a proposed interview guide, following approval by the University research panel, in accordance with ethical guidelines for undertaking qualitative research (Jones, 2014). In developing a semi-structured interview guide, an event already experienced by the interviewees, the 2019 Doha World Athletics Championships, was used as the basis for the research questions. The structure of the interview guide consisted of five topics, the first three were based on the actual time schedule (i.e. training preparation, implementation and followup), whilst the last two covered more complex topics. Prior to the start of the interview, the participants were made aware of relevant ethical considerations (e.g. anonymity, right of withdrawal) and their informed consent was once again sought. In addition, the interviewees were given a further introduction to the study with the opportunity to ask questions (Jones et $a l ., 2012)$. Following the interviews, thematic analysis was used to explore the data whereby themes and patterns emerging from the data were identified and categorised (Holloway, 2008).

\section{Results and discussions}


Following an overview of existing literature, as is standard procedure in qualitative research (Holloway et al., 2010), this study will now allow the data to take primacy. Four dominant key themes emerged from the data. These are the importance of preparation (training, strategic approaches, and personal safety and risk issues); the unique challenges of competition day (organisational aspects, race experience, and emotional experience); the need for sports event retrospection (strategy, personal observation, and athlete recommendations); and prioritising elite event athlete perspectives and opinions at ISEs (allocation of sports events, advocating athletes, mega event marathons, and ensuring athlete safety).

\subsection{The heat is on: Preparation and training for international sports events}

The first key theme emerging from the data was the central role of preparing and training for world championship level events. All four athletes stayed in their home country during the training preparation except athlete 2 who prepared at a high-altitude training camp (HATC) at 2400 metres altitude in Iten, Africa (HATC 2020) for a period of two weeks. She highlighted 'I don't mind the heat. I'm used to it so I actually thought Doha would be a good opportunity for me to compete against others, because I know I'm quite good with running in the heat'. Athlete 1 trained in Europe, chosen mainly because of proximity to home, but which offered the important advantage of altitude training at 2030 metres and climatically favourable conditions, noting 'I was in a dilemma because at home we have a lot of humidity, so I should have an advantage'. Athletes 3 and 4 came from climatically cooler countries, although they did perceive this as problematic in terms of their adaptation. Athlete 3 observed 'the problem in Doha was not the warmth - it was about thirty degrees which was OK, but it was the air that was the problem, as at home you can't get this air - so it was very difficult to train'. 
Strategic planning represented the most significant factor in the training preparation of all athletes. Adapting to the competition start time was especially emphasised. Athlete 4 followed a special sleep adaptation plan, in accordance with studies that confirm endurance athletes need more sleep because of their physical and mental demands (Bender et al., 2018). Heat acclimatisation emerged as a key training consideration. Athlete 4 indicated ' $I$ made sure the bulk of my harder training was in the heat of the afternoon and then I jumped in the sauna'. This approach was supported by both Alonso (2016) and Tyler (2019) who recommend daily training over 60 minutes in the heat as an acclimation strategy for competitions under hot conditions. Three of the four athletes also included artificially induced heat adaption to their daily training by using sauna sessions in order to stimulate heat adaption (Stanley et al., 2015). Athlete 2 outlined she 'was doing the sauna every single day for about forty minutes to get prepared for the heat and humidity'.

One measure applied by the two athletes from the cooler countries, was training in more clothes, with athlete 4 commenting 'on hot, humid runs I would wear long sleeves and long socks and long shorts to make myself feel even hotter.' Tyler (2019) illustrated that overdressing was not as effective as other methods of increasing physiological strain, although still an effective alternative for training in cooler environments. Athlete 3 was the only athlete to include adaptation training linked to the physical ability to increase water absorption and storage, explaining 'I tried to drink when I was on the treadmill to drink very cold sport drinks, and to drink more than before'. This strategy is referred to as super hydration and results in increased blood plasma volume and lower core temperature and heart rate during activity (Benardot, 2011). 
Two athletes experienced difficulties in their training preparation due to injuries. Athlete 2 emphasised 'I had a stress fracture, so it was impossible for me to run for more than a year. I then over trained. I overdid it because I was so excited that I qualified for Doha'. High levels of motivation among athletes is a condition for achieving high performance, but this can also develop into a manifestation known as excessive motivation, and this form of motivation can lead to burnout or overtraining as described by athlete 2 (McKenzie, 1999).

As race day approached, strategic preparations intensified for the athletes, who all followed taper sessions, a pre-competition training phase in which the training load is gradually reduced over time to allow physiological and psychological recovery from accumulated training stress, with the goal of maximising competition performance (Mujika et al., 2004). As in the preparation training, special attention was paid to the competition start time around midnight, with athlete 3 noting 'because the race was at night, when I arrived in Doha I would do one session during the day in the heat and one session at the evening, close to race start time'. The most frequently mentioned strategic preparation linked to cooling was that of hydration. All athletes worked with different sport drink manufacturers to maintain their carbohydrate-electrolyte balance. This was important to replace sweat loss, increase carbohydrate metabolism and reduce stress on the cardiovascular system (Murray 2007).

As an additional measure for pre-cooling, three athletes used an ice-vest in their planning, with athlete 3 commenting 'my coaches arranged this cooling vest for me'. However, Jones et al., (2012) found that wearing an ice vest does not significantly improve training performance, as no significant effect on the body core temperature could be proven. Athlete 4 considered an alternative strategic cooling option, which include frozen towels and caps, mentioning 'I brought my own towels and hats with me and the team provided us the ice'. 
Due to the expected high temperatures on competition day all athletes planned a cautious race strategy from the outset. Athlete 4 spoke on behalf of all athletes by stating 'We knew it was gonna be a race of attrition'.

In relation to personal safety and risk, Hanstad (2012) emphasises the importance of risk management prevention and that any negative factor can affect the ability of athletes to perform optimally. For coaches and especially for athletes, participation in extreme climatic conditions is often a new experience, which requires significant attention during the event preparation stage. As Hanstad indicates, participation of an athlete can be terminated prematurely or, in the worst case, lead to serious injury or death of an athlete. As such, the athletes all viewed the provision of information about the risks of participating in Doha as critical. Athlete 4 noted 'I did my own reading so I knew the risks, but I don't remember the local organising committee or my federation providing us with information on what those risk were'.

All of the athletes interviewed shared similar concerns about high humidity and its effects on their physical performance, and the term 'afraid' was used several times. Athlete 1 explained 'the most difficult part wasn't the heat - it was the humidity that I was afraid of', and similarly athlete 4 noted 'I went back and forth and I cried a lot. I was really afraid especially as I saw the temperature creeping up'. These thoughts and emotions were consistent with findings of Hammermeister \& Burton (2016) who reported on the impact of thoughts of endurance athletes on their emotional reactions and behaviour. Athlete 4 shared concerns about her personal heat resistance due to her menstrual cycle, observing: 
heat better. Unfortunately, where I was in my cycle the odds were against me for managing heat and humidity because my core temperature was already up'

These concerns were supported by Burrows \& Bird (2000) who identified that the menstrual cycle causes cyclical changes in core body temperature, with a premenstrual temperature increase and postmenstrual temperature decrease, before a return to baseline.

The findings from the first key theme have identified challenges in the training preparations were linked to both geographical location and the associated difficulty in achieving a temperature acclimatisation, especially regarding humidity (Gerrett et al., 2019). The logistics of changing training locations or training camps were often not feasible due to personal reasons and / or the limited support of national federations (Slack et al., 2021).

\subsection{The unique challenges of competition day}

The pre-event challenges continued in the imminent lead up to, and during the competition. The athletes all discussed organisational and communicative problems stemming from the competition organisers, which led to misunderstandings from the athletes and confusion surrounding the health hazards linked to the climate conditions on the competition day. The lack of competition information for athletes and inadequate briefings for volunteers were mentioned. The experiences of the athletes reflect the importance of training people who interact with both the spectators and athletes during the event (Greenwell et al., 2014), if that event is to be perceived as successful. Athlete 2 commented 'we brought drinks that we were supposed to drop later, and some of the drinks were confiscated. I didn't understand why? I had my own electrolyte prepared, and they wanted to take it?'. Johnson \& Pedowitz (2007) 
state the importance of communicating with the athletes' pre-race, on the competition day.

Further to issues relating to safety, athlete responses differed in their perception of the medical precautions on the day of the competition. Athletes 1 and 3 indicated they felt safe in terms of access to, and visibility of, medical care during the marathon. In contrast, athlete 2 identified a lack of medical support available after she dropped out of the race, stating ' $I$ actually had to find a way to get off the course. No one saw me, noticed me or wanted to help or anything'. All athletes were critical of the inadequate supply of much needed cold water by the organisers. Athlete 3 noted 'It was only water and it was not cold water. They had some small water bottles standing on a table which you had to go and pick up and pour over your head'. Mündel et al., (2006) highlight that a cold fluid has a heat-lowering effect compared to a drink with a more neutral temperature, thus reducing the effects of thermal stress on the body and extending time taken to reach an exercise-limiting core temperature. Athlete 4 also explained the ineffectiveness of the sponges provided and difficulties caused by the irregular distribution of the water stations, observing:

'They had sponges, but when you squeezed out water, it was as if it was just chemicals. It was like using soap and having a bath. They were hot, they didn't cool you down, and then you just poured this warm water out of a bottle'.

In terms of the race experience, all athletes noted that despite planning to start the race cautiously, they were surprised at how exhausting the race felt. Athlete 1 commented ' $I$ thought I could go faster muscularly, but when I went faster, I just couldn't breathe' whilst athlete 4 highlighted: 
'Goal one was to finish, goal two was not to die, and goal three was to finish in the top ten. In retrospection, I should have switched goals one and two. Goal one should have been - don't die, and goal two should have been to finish the race'.

The most extensive responses from the athletes focused on the physical symptoms experienced during the competition, and they all discussed their individual pain experiences of running the marathon (Shipway and Jones, 2008). Heat cramps or muscle cramps, as experienced by athlete 1 , occur particularly during physical exertion in hot and humid environments due to dehydration, depletion of electrolytes, and sodium losses from sweat (Becker and Stewart, 2011). Athlete 1 noted 'the realistic alarm was when I had very intense spasms in my abdominals and I stopped. I couldn't breathe', whilst both athlete 2 and athlete 4 confirmed some of the symptoms of heat exhaustion mentioned by Becker \& Stewart which include headache, weakness, dizziness, goose bumps, nausea, vomiting, diarrhoea, irritability and loss of coordination. For both athletes, this included stomach problems and the appearance of goose bumps. Athlete 4 observed:

'After eighteen kilometres, I stopped sweating which was an early sign of heat stroke and heat stress. Then, around the half marathon point, I started to get goose bumps and every time I picked up the pace the goose bumps increased. I knew what was coming and I knew what was happening to me, and so I just said - I have to stop!'

During the race, the main cooling strategy used by all athletes, besides constant hydration, was pouring water over the body. This reduces the skin temperature before it leaves the body and improves thermal comfort (Maughan and Shirreffs, 2004; Tyler, 2019). Athlete 2 reflected how 'During the race, I put water all over my body and on my head. Also, we had 
ice. I put ice in my sport top and everywhere else'. The phenomenon of collapsing was referred to by athlete 1 and is common among athletes after the finish (Shipway and Jones, 2008), often due to hypotension and dehydration. She commented 'when I finished, I lost a little bit my senses. I collapsed'. Similarly, athlete 4 discussed experiences at the finish, explaining 'they put towels on me to reduce my temperature. I didn't start vomiting but I started dry heating for ten minutes. I was in physical distress'. The treatment both athletes received was consistent with the recommendations of Sallis (2005).

In relation to emotional experiences, both negative and positive feelings were mentioned. Noteworthy were the observations of athlete 4 , whose recollections aligned with the emotions of numerous other athletes who were confronted with feelings of shame and hopelessness, which were expressed by crying. Athlete 4 was exasperated when observing:

'I definitely had my moment of 'oh my god I just dropped out of worlds' and I had a cry. There were lots of tears out on the course. We were all put into such an unfair situation. It was an untenable situation'.

Finally, feelings of pride were mentioned by athlete 1 and 2 who both finished the marathon. Athlete 2 associated her positive feelings with the satisfaction of finishing the marathon for her partner, out of guilt for sacrifices he had made during her preparations for the event. In summary, challenges addressed on the day of the competition included the reoccurring lack of provision and communication of important information by the organising committee, especially in the context of climate risk. Individual difficulties during the competition dealing with temperature and humidity were extensively mentioned, whereby heat illness symptoms of dehydration occurred (Murray, 1996). These challenges highlight the apparent priority 
given to aspects of event organisation and delivery, often to the disadvantage of the athletes.

\subsection{Looking back to the future: Elite athlete retrospection}

Upon reflection, after the event, the decision of the athletes to participate was a mixture of different motivations; first, the global status of the events and second, the honour of representing their country (McNamee and Parry, 2014). Athlete 4 commented that 'my desire to wear the jersey and represent my country was what drove me to want to compete to the best of my abilities', whilst athlete 2 noted 'even if the race was held in the Sahara I would have gone. Ijust wanted to go. The World Championships - for me it was a big thing'.

With regards to post event reflection on specific preparation and training tactics, three of the four elite athletes recommended a period of more than ten day for in-country acclimatisation, consistent with the findings of Maughan and Shirreffs (2004) and Lanham-New et al., (2011). Athlete 3 reflected 'I think it would have been much better if I'd been in Doha one month beforehand. I think you have to be there for more than ten days'. In connection with the chosen cooling strategies applied before and during the competition, the majority of athletes did not find ice vests helpful with athlete 2 noting 'obviously I wouldn't run with it during the race. I just had it on in the warm up. I don't think it really helped, to be honest'. Meanwhile, athlete 1 emphasised the immersion with ice and water as particularly helpful.

When asked what the athletes would recommend to the organisers of the world championships in terms of the protection and safety of the athletes, there was clear feedback on the utmost importance to have postponed or rescheduled the women's race, given the weather conditions. This observation highlights the difficulty for event organisers to find the 
right balance between the needs of the athletes and the objectives of the ISE, especially given that the women's marathon took place on the opening day. This was acknowledged by athlete 4 who observed

'I understand it was the opening night and that's fine, but at what risk? They (the organisers) put the women at way too high of a risk. It was really disappointing to see that given the horrendous conditions we faced, they didn't postpone the race'.

The participants all commented on the need for better provision of information to the individual athlete by all the organisations involved, including local organising committees, the IAAF, and the individual national federations. The athletes also discussed the need for improved 'event day' communication and organisation, suggesting the provision of water showers and fans, as alternative cooling strategies, with athlete 3 suggesting 'I think organisers in Doha could have provided showers we could run through, or some form of air conditioning on parts of the road'. An appeal to the organisers was made by athlete 4, requesting 'do what is best for the athletes and not necessarily what's best for the local organising committee’.

When reflecting on training for the marathon in Doha, both athlete 3 and athlete 4 agreed that early training preparation for heat acclimatisation should occur within the host region, although this is often difficult to implement for both personal and economic reasons. Athlete 3 felt 'I needed to be there longer, and needed to be doing longer sessions', supported by the perspective of athlete 4 who noted 'Do I think I needed to train in Doha at midnight to set myself up for better success? Sure. Was that economically feasible? No'. 
All athletes repeatedly emphasised how severe the climatic conditions had been on their health. In particular athlete 4, who had studied the risks in detail prior to the marathon, recalled her experiences of the athlete recovery zone:

'Athletes were moaning and in distress. I remember thinking - this is not right. We should not do this to athletes. Especially considering the long-term risks of basically putting your organs in that temperature for an elevated amount of time, and just how dangerous that can be'.

The high number of athlete DNF's (Did Not Finish) in the women's marathon, due to the climatic conditions, was a significant topic of debate. The athletes had contrasting perspectives on whether finishing the marathon was connected to either their country of origin or residence during their preparation stage. Athlete 1 felt there were a combination of both physical and psychological factors, noting 'I think the mind helps us to finish and also because I come from a similar climate. The athletes that were from north Europe - most of them gave up'. Athlete 4 suggested 'I think the athletes that finished were the ones who just have a physiology that can withstand heat better than others'. This observation was consistent with the findings of Neumann et al., (1999) who attributed the athlete's ability to resist heat to acclimatisation training, which reduces body core temperature and has a positive effect on earlier sweating and faster cooling. Neumann et al., also noted the ability to deal with heat differs from person to person.

The participants suggested that an often-underestimated consequence is the mental recovery after a marathon. Athlete 4 described her experience in the weeks following the marathon, explaining 'I felt like a failure. I felt like I had let my coaches, my parents and my family 
down'. This is a common experience among marathon runners (Shipway and Jones, 2008). In summary, findings from this theme highlight the extraordinary challenges athletes faced in the pre, during and post event periods, and reinforces the need for reconsidering the elite athlete's role in decision-making processes surrounding international sports events.

\subsection{Prioritising the perspectives and opinions of elite athletes at international sports events (ISEs)}

Following the Doha World Championships and a period of post-event reflection, three prominent sub themes dominated discussions, notably (i) future major and mega sport events; (ii) implementing measures to ensure athlete safety; and (iii) mechanisms to better advocate the perspectives of the athlete.

After experiences at the 2019 Doha World Championships, the IOC (International Olympic Committee) moved their endurance events to cooler conditions $800 \mathrm{~km}$ north of Tokyo in Sapporo on the Japanese island of Hokkaido. This decision was prompted due to predicted hot and humid conditions in Tokyo during the games. According to Wu et al., (2020), who compared the thermal comfort between Sapporo and Tokyo, Sapporo offers less heat stress conditions and convenient thermal comfort. This decision was supported by the athletes, especially athlete 3 who noted 'they made the right decision, and should have made it when awarding the Games to Tokyo. They have learned some really important lessons from Doha, and those lessons are not surprising'. The athletes were asked about their own individual learning outcomes from competing in Doha, and how that might influence their future training and preparation strategies for the Tokyo Games. Due to the postponement of the Tokyo Games, the athletes were unable to provide specific information about future training 
strategies, as the postponement had changed the qualification processes and timescales.

In terms of introducing measures to ensure athlete safety at future events, the athletes were all opposed to replacing the marathon event with a half-marathon, all passionately arguing that the two distances are just too different. Another proposed measure to ensure safety for athletes was a temperature pill, swallowed by the athletes a few hours before the event. This pill then provides real time information about the body core temperature during the competition (Dineen, 2019). Prior to the Doha event, athletes were asked to participate in the study, and only athlete 4 participated. Athletes 1 and 3 were both reluctant to participate due to limited information and not wishing to risk any potential physiological effects, with athlete 3 stating 'Yes, I'd heard about it but we had no real information'. Upon reflection by the athletes, they indicated there was often a lack of knowledge on the part of athletes and trainers about acclimatisation strategies. Athlete 4 advocated the development of strategies that are then made available to athletes, noting:

'There are global heat scientists out there that should come together and devise various strategies that all athletes could have access to, and publish that information in a public forum. Athletes could then trial approaches that best suit them. Then, when host nations are selected, be they in hot or cold climates, why wouldn't you make that information available to athletes and staff immediately?'

It is logical that only by creating an awareness of the risk factors can the prevention of heatrelated illnesses be prevented (Coris et al., 2004). Athlete 4 was acutely aware of the risks associated with high temperatures noting: 
'A couple of athletes posted on social media about how proud they were that their core temperatures reached $42^{\circ} \mathrm{C}-43^{\circ} \mathrm{C}$. I was like; do you realise the long-term damage on your organs? You don't realise, but it's so dangerous what you just did. I'm sure many athletes didn't do sufficient research, and didn't fully understand the risks'.

At the end of the interviews, the athletes were asked whether, in hindsight, and given the negative factors associated with the 2019 Doha World Championships. would they still have participated in the competition? All athletes answered without hesitation that they would participate again, despite their negative experiences. Athlete 4 actually suggested that refusing to participate in such events might be the only measure to finally set an example for governing bodies /federations to learn to prioritise the needs of their athletes in the future:

'there's so few opportunities to represent your country, but athletes must consider the long-term effects. As athletes, we need to band together and stand up to the IAAF and tell them they need to do what's best for us, and not what is best for their financial balance sheet'.

Regarding selecting future host nations, athlete 1 spoke on behalf of all athletes indicating they would always favour a location which provided support for all stakeholders involved, including the athletes. Athlete 3 further emphasised that the first priority should be to create conditions in which a marathon can be staged without health risks for the athletes. All athletes emphasised the difficulties for athletes to raise public awareness of their perspectives and opinions, and to influence event organisation and implementation. It was apparent they had no option but to accept decisions of organisers, international and national 
federations. Athlete 3 noted that the only current mechanism to speak for themselves was withdrawing from the competition, and the subsequent negative consequences of such decisions. Athlete 4 reflected 'it's very challenging to get athletes to come together and withdraw. They will lose sponsorship, be called names, be singled out, and be ostracised. There's no way to advocate for ourselves. Athlete 1 also reflected 'It would be very good if our voice could be heard, but when some countries have the money, they can fix this, and do whatever they want'. In support of past calls for proactive measures (Parent and Chappelet, 2017), there is now a clear and present need for the athlete voice to exert greater influence.

\section{Conclusions and future directions}

The originality and value of this paper is the unique access to elite female endurance athletes competing in high-profile world championship events. In doing so, it has been possible to explore their perspectives on training, preparation and competing on a global stage. The findings advocate a paradigm shift towards prioritising athlete welfare by event organisers, host destinations, international governing bodies of sport, and national sports federations.

Based on the learned elite athlete experiences, Figure 1 highlights athlete perspectives on the challenges of managing athlete preparation and performance at international sports events (ISEs) hosted in extreme climatic conditions. It identifies seven key areas, whilst highlighting the athlete's ability to influence and control individual challenges.

Insert Figure 1 Here: Understanding Endurance Athlete Perspectives on competing in extreme climatic conditions 
The lower right section of Figure 1 profiles the non-influenceable components for the individual when dealing with difficult climatic conditions (Marquardt, 2009), entitled (i) 'genetic predisposition' and (ii) sport event allocation' (Parent and Chappelet, 2017). The wider sphere of semi-influenceable areas include the (iii) sport event organisation and (iv) arrival strategy. Both these aspects are controlled by various federations, organisations and confederations, whereby the athletes can potentially exert some influence through the local systems, although at present this has little or no effect on change, due to the hierarchicalmonopolistic structure of sport (Shipway and Miles, 2019). The most outlying issues, and therefore areas that athletes can exert more influence, are the combination of (v) training preparation, (vi) strategic preparation and (vii) safety and risk measures. Due to the possibility of affecting these three sub-areas, further research is advocated to adopt aspects of Figure 1 as a possible model for change, and to explore ways to influence the challenges faced by elite athletes competing under extreme climatic conditions at ISEs.

Gaining insider access to elite athletes, competing at the very pinnacle of their respective sports is notoriously problematic. The sample size for this study whilst relatively small, is unique. This is a reflection of (i) challenges of gaining unfiltered access to elite athletes; (ii) reluctance of elite athletes to be interviewed for research purposes; and (iii) the reality that there is an extremely small pool of athletic talent competing on a global stage at the very peak of their sport, who are available and willing to discuss their experiences of elite level competition. Given these practical barriers and restrictions, this represents a good sample size (Sheppard-Marks et al., 2020). Future studies would benefit from comparing and contrasting the male athlete perspective. However, whilst there might be variations in gender perspectives, recent research on thermal response between genders indicates no significant difference (Chang and Kajackaite, 2019). 
The findings have practical and social implications for athletes, national governing bodies of sport, international federations, and sport event organisers, in better understanding issues and barriers surrounding elite athlete preparation and competition at international sports events hosted in unfavourable climatic conditions. The findings also have implications for a diverse range of alternative individual endurance sports and team sports that take place in diverse extreme climates, be they hot, humid or cold environments.

The findings highlight the need for both event organisers and international governing bodies of sport to reconsider the elite athlete's role in decision-making processes surrounding international sports events. The results indicate that event planning rarely considers, or is carried out, in consultation or partnership with the athletes. Given the ethical issues surrounding potential health risks for athletes competing in unfavourable and extreme climatic conditions, this study calls for the prioritisation of the athlete voice by both the organising committees of international sports events and national sports federations, in order to protect athlete welfare and safety.

Similarly, the findings have implications for non-elite participants across the spectrum of abilities participating globally in (non-elite) endurance events, such as the Marathon. In reality, all marathon participants irrespective of speed or ability will face many of the challenges encountered by elite athletes competing in unfavourable climatic conditions. As such, there are lessons to be learnt at all levels of active participation at sports events. As previously highlighted, a key social implication of the findings focuses on decisions taken by global sports federations to host major championships in extreme climatic environments, and the potentially negative physical, health and psychological impacts upon the athletes. Likewise, an additional future research opportunity would be coordinating global scientists to 
create joint research projects on the preparation, implementation and post event evaluation of sport competitions in extreme climate conditions.

A further recommendation linked to the findings suggest that 'new' nations contemplating bidding for international sports events and tournaments should consider the Athlete-Event Paradox surrounding major sports events as an integral part of their decision-making process. A contrast clearly exists between the objectives of (i) global sports federations awarding tournaments, (ii) host nations in developing countries that are bidding more for political and/or image building reasons, and (iii) the subsequent potential for negative and destructive impacts upon athlete welfare.

To conclude, we return to where the study began. As Parent \& Chappelet (2017, p.125) highlight 'without the athlete, there is no sport event and spectacle for consumers, there is no entertainment'. As such, these findings postulate that if international sports events are to flourish and prosper, they must take far greater measures to protect one of their most important assets - the athletes.

\section{References}

Alonso, J.-M., (2016), Bringing the Games to the World II - Environmental Challenges to Athlete Health and Performance in the Heat, Aspetar Sports Medicine Journal, Vol. 5 No.1, pp. 36-39.

Becker, J. A. and Stewart, L. K., (2011), Heat-related Illness, American Family Physician, Vol. 83 No. 11, pp.1325-1330. 
Benardot, D., (2011), Advanced Sports Nutrition. 2nd ed, Human Kinetics, Inc, Champaign, IL.

Bender, A. M., Lawson, D., Werthner, P., and Samuels, C. H., (2018), The Clinical Validation of the Athlete Sleep Screening Questionnaire: an Instrument to Identify Athletes that Need Further Sleep Assessment, Sports Medicine - Open [online], Vol. 4 No. 1, Available from: https://pubmed.ncbi.nlm.nih.gov/29869021/.

Burrows, M. and Bird, S., (2000), The Physiology of the Highly Trained Female Endurance Runner, Sports Medicine, Vol. 30 No. 4, pp. 281-300.

Boucher, A., (2017), Power in elite interviewing: Lessons from feminist studies for political science, Women's Studies International Forum, Vol. 62, pp. 99-106.

Casa, D. J., (1999), Exercise in the Heat. I. Fundamentals of Thermal Physiology, Performance Implications, and Dehydration, Journal of Athletic Training, Vol. 34 No. 3, pp. $246-252$.

Chan, G., (2019), Use of the Wet Bulb Globe Temperature in NCAA FBS Athletic Training Staffs, All Graduate Plan B and other Reports [online], 1366. Available from: https://digitalcommons.usu.edu/cgi/viewcontent.cgi $?$ article $=2392 \&$ context=gradreports.

Chappelet, J.-.L. and Parent, M. eds., (2017), The (Wide) World of Sports Events. In Parent, M. and Chappelet, J.-.L., Routledge Handbook of Sports Event Management, Routledge, London, pp. 1-17. 
Chang, T. Y. and Kajackaite, A., (2019), Battle for the thermostat: Gender and the effect of temperature on cognitive performance. PLoS ONE [online], Vol. 14 No. 5, Available from: https://journals.plos.org/plosone/article?id=10.1371/journal.pone.0216362.

Cheuvront, S. N. and Haymes, E. M., (2001), Thermoregulation and Marathon Running Biological and Environmental Influences, Sports Medicine, Vol. 31 No. 10, pp. 743-762.

Close, P., Askew, D., and Xin, X., (2006), The Beijing Olympiad: The Political Economy of a Sporting Mega-Event, 1st ed, Routledge, London.

Coris, E. E., Ramirez, A. M., and Van Durme, D. J., (2004), Heat Illness in Athletes: The Dangerous Combination of Heat, Humidity and Exercise, Sports Medicine, Vol. 34 No. 1, pp. $9-16$.

Dashper, K., (2012). The Olympic Experience from a Distance: The case of the equestrian events at the 2008 Games. In: Shipway R. and Fyall A., eds. International Sports Events: Impacts, Experiences and Identities. Routledge, Oxford. pp. 141-153.

Dashper, K., Fletcher, T., and Mccullough, N., (2015), Sports Events, Society and Culture, Routledge, New York.

Delaney, K., (2007) Methodological Dilemmas and Opportunities in Interviewing Organizational Elites, Sociology Compass, Vol. 1 No. 1, pp. 208-221.

Dineen, R. (2019), Exclusive: Electronic pill that protects against heat exhaustion to be 
trialled in Doha, The Telegraph [online], 20 August 2019, Available from:

https://www.telegraph.co.uk/athletics/2019/08/20/exclusive-electronic-pill-protects- againstheat-exhaustion-trialled/.

Dowse, S. and Fletcher, T. (2018), Sport mega-events, the 'non-West' and the ethics of event hosting, Sport in Society, Vol. 21 No. 5, pp. 745-761.

El Helou, N., Tafflet, M., Berthelot, G., Tolaini, J., Marc, A., Guillaume, M., Hausswirth, C., and Toussaint, J. F., (2012), Impact of Environmental Parameters on Marathon Running Performance. PLoS ONE [online], Available from:

https://journals.plos.org/plosone/article/citation?id=10.1371/journal.pone.0037407

Garrett, W. E. and Kirkendall, D. T., eds., (2000), Exercise and Sport Science, 1st ed. Lippincott Williams \& Wilkins, Philadelphia.

Gerrett, N., Kingma, B. R. M., Sluijter, R., and Daanen, H. A. M., (2019), Ambient Conditions Prior to Tokyo 2020 Olympic and Paralympic games: Considerations for Acclimation or Acclimatization Strategies. Frontiers in Physiology [online], Vol. 10, p.414, Available from: https://pubmed.ncbi.nlm.nih.gov/31068829/.

Greenwell, T. C., Danzey-Bussell, L. A., and Shonk, D. J., (2014), Managing Sport Events, 1st ed, Human Kinetics, Inc, Champaign, IL.

Grix, J. and Lee, D. (2013), Soft Power, Sports Mega-Events and Emerging States: The Lure of the Politics of Attraction, Global Society, Vol. 27 No. 4, pp. 521-536. 
Guy, J. H., Deakin, G. B., Edwards, A. M., Miller, C. M., and Pyne, D. B., (2015), Adaptation to Hot Environmental Conditions: An Exploration of the Performance Basis, Procedures and Future Directions to Optimise Opportunities for Elite Athletes, Sports Medicine, Vol. 45 No. 3, pp. 303-311.

Hammermeister, J. and Burton, D., (2016), Anxiety and the Ironman: Investigating the Antecedents and Consequences of Endurance Athletes' State Anxiety, The Sport Psychologist, Vol. 9 No. 1, pp. 29-40.

Hanstad, D. V., (2012), Risk Management in Major Sporting Events: A participating National Olympic Team's Perspective, Event Management, Vol. 16 No. 3, pp. 189-201.

HATC, (2020), About HATC [online], [Accessed 25 May 2020], Available from: https://hatc-iten.com/

Henderson, J. C., (2016), Hosting the 2022 FIFA World Cup: opportunities and challenges for Qatar, Journal of Sport \& Tourism, Vol. 19 Nos. 3-4, pp. 281-298.

Holloway, I. (2008), A-Z of Qualitative Research in Healthcare and Nursing, Blackwell, Oxford.

Holloway, I. and Wheeler, S. (2010), Qualitative Research in Nursing and Healthcare, 3rd ed, Wiley-Blackwell, Oxford. 
Holloway, I. Brown, L. and Shipway, R. (2010), Meaning not measurement: Using ethnography to bring a deeper understanding to the participant experience of festivals and events, International Journal of Event and Festival Management, Vol. 1 No. 1, pp. 74-85.

Holt, R. and Ruta, D., eds., (2015), Routledge Handbook of Sport and Legacy: Meeting the Challenge of Major Sports Events, Routledge, London.

Houlihan, B., (2004), Civil Rights, Doping Control and the World Anti-doping Code, Sport in Society, Vol. 7 No. 3, pp. 420-437.

Ingle, S. (2019), Doha world championships 'a disaster', says decathlon record-holder Mayer, The Guardian [online], 28 September 2019, Available from:

https://www.theguardian.com/sport/2019/sep/28/world-athletics-championships-doha.

Ishac, W., (2018), Furthering national development through sport, the case of Qatar [online], Bourgogne, Available from: https://tel.archives-ouvertes.fr/tel-02071444.

Jarvie, G., (2006), Sport, Culture and Society: An Introduction, Routledge, London.

Johnson, D. H. and Pedowitz, R. A., (2006), Practical Orthopaedic Sports Medicine and Arthroscopy, Lippincott Williams \& Wilkins, Philadelphia.

Jones, I., (2014), Research Methods for Sports Studies. 3rd ed. London, Routledge.

Jones, P. R., Barton, C., Morrissey, D., Maffulli, N., and Hemmings, S., (2012), Pre-cooling 
for endurance exercise performance in the heat: A systematic review, BMC Medicine, Vol. 10 No. 166, pp. 1-19.

Jones, I., Brown, L. and Holloway, I., (2012), Qualitative research in sport and physical activity, Sage, London.

Kakamu, T., Wada, K., Smith, D., Endo, S., and Fukushima, T., (2017), Preventing Heat Illness in the Anticipated Hot Climate of the Tokyo 2020 Summer Olympic Games, Environmental Health and Preventive Medicine, Vol. 22 No. 68, pp. 960-1295.

Knott, B., Fyall, A. and Jones, I., (2017), Sport mega-events and nation branding: Unique characteristics of the 2010 FIFA World Cup, South Africa, International Journal of Contemporary Hospitality Management, Vol. 29 No. 3, pp. 900-923.

Ko, Y. J., Zhang, J., Cattani, K., and Pastore, D., (2011), Assessment of event quality in major spectator sports, Managing Service Quality, Vol. 21 No. 3, pp. 304-322.

Krouwel, M., Jolly, K., and Greenfield, S., (2019), Comparing Skype (video calling) and inperson qualitative interview modes in a study of people with irritable bowel syndrome-an exploratory comparative analysis, BMC Medical Research Methodology, Vol. 19 No. 219, pp. 1-9.

Lancaster, K., (2017), Confidentiality, anonymity and power relations in elite interviewing: conducting qualitative policy research in a politicised domain, International Journal of Social Research Methodology, Vol.20 No.1, pp. 93-103. 
Lanham-New, S. A., Stear, S. J., Shirreffs, S. M., Collins, A. L., and Budgett, R., eds., (2011), Sport and Exercise Nutrition, Wiley-Blackwell, Oxford.

Maennig, W. and Zimbalist, A., eds., (2012), International Handbook on the Economics of Mega Sporting Events, Edward Elgar Publishing, Cheltenham.

Marquardt, M. J., ed., (2009), Human Resources and Their Development - Volume II, Eolss Publishers Company Limited, Oxford.

Matzarakis, A. and Fröhlich, D., (2015), Sport events and climate for visitors - the case of FIFA World Cup in Qatar 2022, International Journal of Biometeorology [online], Vol. 59, pp. 481-486. Available from: https://link.springer.com/content/pdf/10.1007/s00484-0140886-5.pdf.

Maughan, R. J. and Shirreffs, S., (2004), Exercise in the heat: Challenges and opportunities, Journal of Sports Sciences, Vol. 22 No. 10, pp. 917-927.

McKenzie, D. C., (1999), Markers of excessive exercise, Canadian Journal of Applied Physiology, Vol. 24 No. 1, pp. 66-73.

McNamee, M. and Parry, J., eds., (2014), Olympic Ethics and Philosophy, 1st ed, Routledge, London.

Mikecz, R. (2012), Interviewing elites: Addressing methodological issues. Qualitative Inquiry, Vol.18, pp.482-493. 
Miller, T., Lawrence, G. L., McKay, J., and Rowe, D., (2001), Globalization and Sport:

Playing the World, 1st ed, SAGE Publications, London.

Montain, S. J., Ely, M. R., and Cheuvront, S. N., (2007), Marathon Performance in Thermally Stressing Conditions, Sports Medicine, Vol. 37 Nos. 4-5, pp. 320-323.

Mujika, I., Padilla, S., Pyne, D., and Busso, T., (2004), Physiological changes associated with the pre-event taper in athletes, Sports Medicine, Vol. 34 No. 13, pp. 891-927.

Mündel, T., King, J., Collacott, E., and Jones, D. A., (2006), Drink temperature influences fluid intake and endurance capacity in men during exercise in a hot, dry environment, Experimental Physiology, Vol. 91 No. 5, pp. 925-933.

Murray, B., (2007), The Role of Salt and Glucose Replacement Drinks in the Marathon, Sports Medicine, Vol. 37 Nos. 4-5, pp. 358-360.

Murray, R., (1996), Dehydration, Hyperthermia, and Athletes: Science and Practice, Journal of Athletic Training, Vol. 31 No. 3, pp. 248-252.

Neumann, G., Pfützner, A., and Berbalk, A., (1999), Successful Endurance Training, Meyer \& Meyer Sport, Germany.

Parent, M. M. and Chappelet, J.-L., eds., (2017), Routledge Handbook of Sports Event Management, Routledge, London. 
Pitts, B. G. and Zhang, J. J., eds., (2016), Global Sport Management: Contemporary Issues and Inquiries, Routledge, New York.

Polio, C. and Friedman, D. A., (2016), Understanding, Evaluating, and Conducting Second Language Writing Research, Routledge, New York.

Ramchandani, G., Coleman, R. J., and Bingham, J., (2017), Sport participation behaviours of spectators attending major sports events and event induced attitudinal changes towards sport, International Journal of Event and Festival Management, Vol. 8 No. 2, pp. 121-135.

Reiche, D. and Sorek, T., eds., (2019), Sport, Politics and Society in the Middle East, Oxford University Press, Oxford.

Sallis, R., (2005), Collapse in the endurance athlete. Sports Science Exchance [online], Vol. 17 No. 4, pp. 95-103. Available from:

http://d.wanfangdata.com.cn/periodical zgydyxzz200505034.aspx.

Sarstedt, M., Ringle, C. M., Raithel, S., and Gudergan, S. P., (2014), In Pursuit of Understanding what drives Fan Satisfaction, Journal of Leisure Research, Vol. 46 No. 4, pp. 419-447.

Sheppard-Marks, L., Shipway, R. and Brown, L., (2020), Life at the edge: exploring male athlete criminality, Sport in Society, Vol. 23 No. 6, pp. 1042-1062. 
Shipway, R. and Jones, I. (2008), The Great Suburban Everest: An 'Insiders' Perspective on Experiences at the 2007 Flora London Marathon, Journal of Sport \& Tourism, Vol. 13 No. 1, pp. 61-77.

Shipway, R. and Fyall, A. eds., (2012), International Sports Events: Impacts, Experiences and Identities, Routledge, London.

Shipway, R. and Miles, L., (2019), Reputation and perceived resilience in developing countries bidding for major sports events, In: Walters, G. and Mair, J., eds, Reputation and Image Recovery for the Tourism Industry, Goodfellow Publishers, Oxford, pp. 148-164.

Shipway, R., Holloway, I. and Jones, I., (2013). Organisations, Practices, Actors and Events: Experiencing Inside the Distance Running Social World. International Review for the Sociology of Sport, Vol 48 No 3, pp.259-276.

Shipway, R., Jago, L. and Deery, M., (2021), Quantitative and Qualitative Research Tools in Events, In: Page, S.J. and Connell, J., eds, Routledge Handbook of Events, Routledge, Oxford, pp. 306-327.

Slack, T., Byers, T., and Thurston, A., eds., (2021), Understanding Sport Organizations: Applications for Sport Managers, 3rd ed, Human Kinetics, Inc, Champaign, IL.

Sofotasiou, P., Hughes, B. R., and Calautit, J. K., (2015), Qatar 2022: Facing the FIFA World Cup climatic and legacy challenges, Sustainable Cities and Society, Vol. 14 No.1 pp. 16-30. 
Suping, Z., Guanglin, M., Yanwen, W., and Ji, L., (1992), Study of the relationships between weather conditions and the marathon race, and of meteorotropic effects on distance runners, International Journal of Biometeorology, Vol. 36, pp. 36-68.

Szubski, C., (2019), Sweltering heat at the 2020 Olympics in Tokyo [online], Available from: https://sportifycities.files.wordpress.com/2019/03/tokyo-2020-olympics- heat-factor-sportifycities-report.pdf.

Tyler, C. J., (2019), Maximising Performance in Hot Environments: A Problem-Based Learning Approach, Routledge, London.

Vihma, T., (2010), Effects of weather on the performance of marathon runners, International Journal of Biometeorology, Vol. 3 No. 54, pp. 297-306.

Wann, D. L. and Pierce, S., (2005), The relationship between sport team identification and social well-being: Additional evidence supporting the Team Identification -Social Psychological Health Model, North American Journal of Psychology, Vol. 7 No. 1, pp. 117124.

Wu, Y., Graw, K., and Matzarakis, A., (2020), Comparison of Thermal Comfort between Sapporo and Tokyo-The Case of the Olympics 2020. Atmosphere [online], Vol, 11 No. 5, pp. 1- 13. Available from: https://www.mdpi.com/2073-4433/11/5/444/htm. 


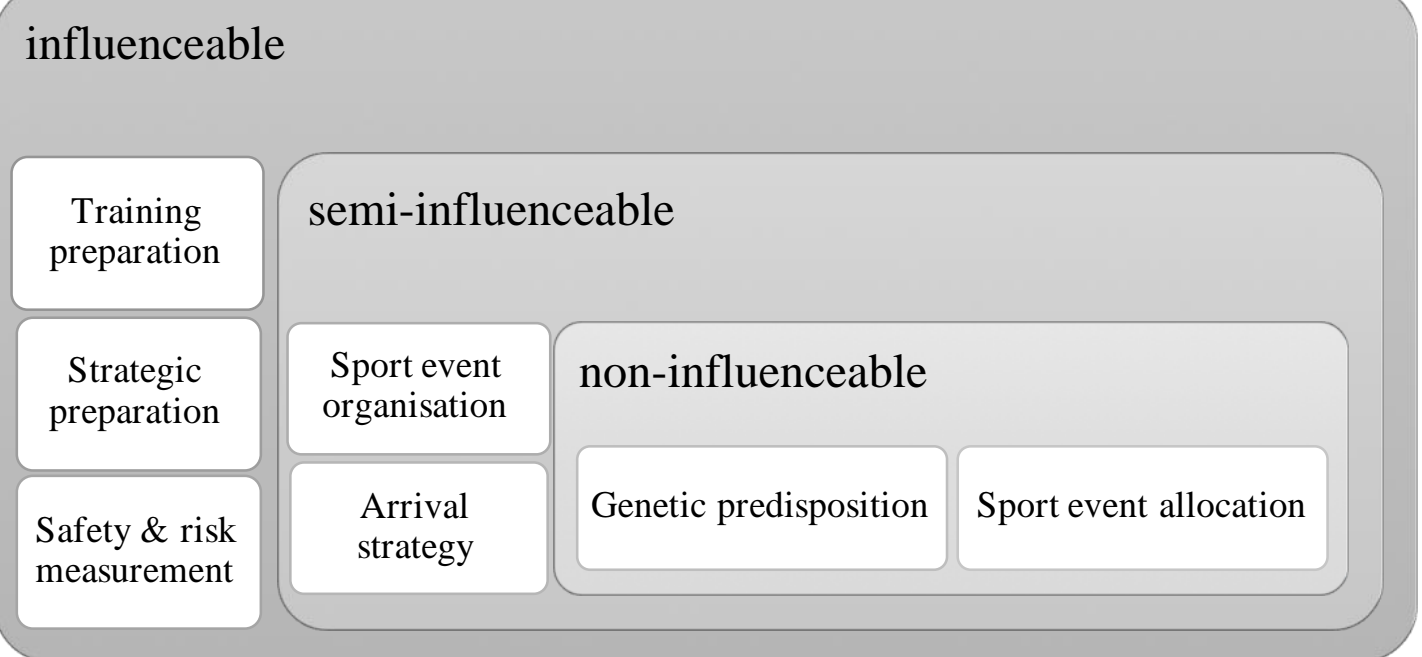

Figure 1: Understanding endurance athlete perspectives on competing in extreme climatic conditions 